\title{
ACCURACY ASSESSMENT OF THE GROUND DEFORMATION MONITORING WITH THE USE OF GPS LOCAL NETWORK: OPEN PIT MINE KOŹMIN CASE STUDY
}

\author{
Radoslaw BARYLA *, Jacek PAZIEWSKI, Pawel WIELGOSZ, \\ Katarzyna STEPNIAK and Marta KRUKOWSKA \\ University of Warmia and Mazury in Olsztyn, Oczapowskiego 1, \\ 10-719 Olsztyn, Poland \\ *Corresponding author's e-mail: baryla@uwm.edu.pl
}

\begin{tabular}{l} 
ARTICLE INFO \\
\hline Article history: \\
Received 15 May 2014 \\
Accepted 18 August 2014 \\
Available online 09 September 2014 \\
\hline
\end{tabular}

Keywords:

GPS

Precise GPS leveling

Deformation monitoring

\section{ABSTRACT}

Ground deformation monitoring at the open pit mine Koźmin has been conducted since 2008 . The principles and results of the precise determination of the three dimensional displacements using GPS technology has been presented in this paper. In specific, establishment of the control network, patented technology of the field measurements, the strategy of GPS data postprocessing, as well as the obtained displacements in the control network with their accuracy analysis have been presented. The research conducted with the developed technology indicates a high accuracy and reliability of the determined displacements of the controlled points.

\section{INTRODUCTION}

Global Positioning System (GPS) measurements are considered as a very useful tool for monitoring deformations of the Earth's crust resulted from the impact of natural forces and human activities. GPS technology offers several advantages over conventional surveying methods. Therefore deformation monitoring and displacement determination with the GPS technology is getting an increasingly common tool and nowadays plays a crucial role in the natural hazard monitoring area (Chen et al., 2000; Wang, 2013). In comparison to the spirit (geometric) leveling, the satellite measurements allow for a larger coverage, productivity and efficiency with similar accuracy (Gili et al., 2000). However, in order to achieve high accuracy of the results, the state of the art equipment and data processing software and algorithms are required (Stepniak et al., 2013). In addition, systematic errors have to be eliminated or at least reduced. In the precise satellite levelling, it is necessary to take into account the influence of the atmospheric delays of the GPS signals. Studies on the reduction of the tropospheric delay in precise surveying applications have been carried out by several research groups (Vey et al., 2006; Wielgosz et al., 2011, Urquhart et al., 2013). The ionospheric delay is also one of the most significant errors in GPS measurements and it should be mitigated during the data processing (Kashani et al., 2007). Therefore advanced modelling techniques for mitigation of the ionospheric and tropospheric refraction have to be applied (Grejner-Brzezinska et al., 2007; Hadaś et al., 2013; Krypiak-Gregorczyk et al., 2013; Sieradzki, 2013). Moreover, satellite and receiver antenna phase center variations as well as errors related to the antenna centering over a surveyed point need to be eliminated (Görres et al., 2006).

In this paper, the results and the accuracy assessment of the control points' displacements using GPS technique in the area of the open pit mine Koźmin of the KWB Adamów in Turek in central Poland (Fig. 1) are presented. The mining area of the KWB Adamów covers about 2000 hectares. The lignite was mined from three pits: "Adamów", "Koźmin" and "Władysławów" until 2012. However, nowadays in the former pit "Władysławów" a water reservoir has been created. In the mining area the mineral deposits are at depths of $30-55$ meters. Each year, about 34 million $\mathrm{m}^{3}$ of the overburden and about 5 million tons of coal are mined and transported to the power station.

Research on improving ground deformation monitoring technology in the vicinity of the Koźmin mine has been conducted since 2008 . Here, the results of 5 annual GPS observing campaigns, carried out since 2008 to 2012, are shown. The technology of 3D ground displacements determination with the use of GPS measurements was already presented in details in (Baryla et al., 2011). The collected GPS data were processed using scientific GNSS postprocessing package - Bernese GPS Software Version 5.0 (Dach et al., 2007).

\section{METHODOLOGY}

\subsection{FIELD CAMPAIGNS AND GPS DATA}

The deformation monitoring has been carried out on the basis of the control network, which consists of 3 local reference/control points (R01-R03) and 


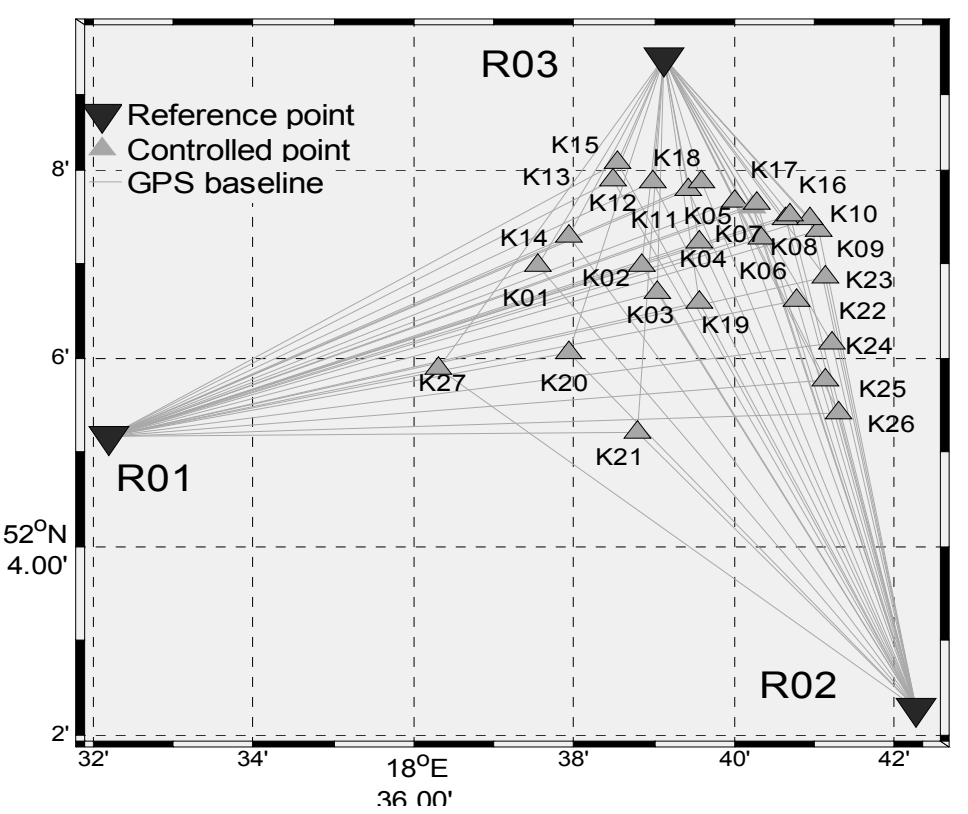

Fig. 1 Control network in the area of the open pit mine Koźmin (source: Baryła et al., 2011).
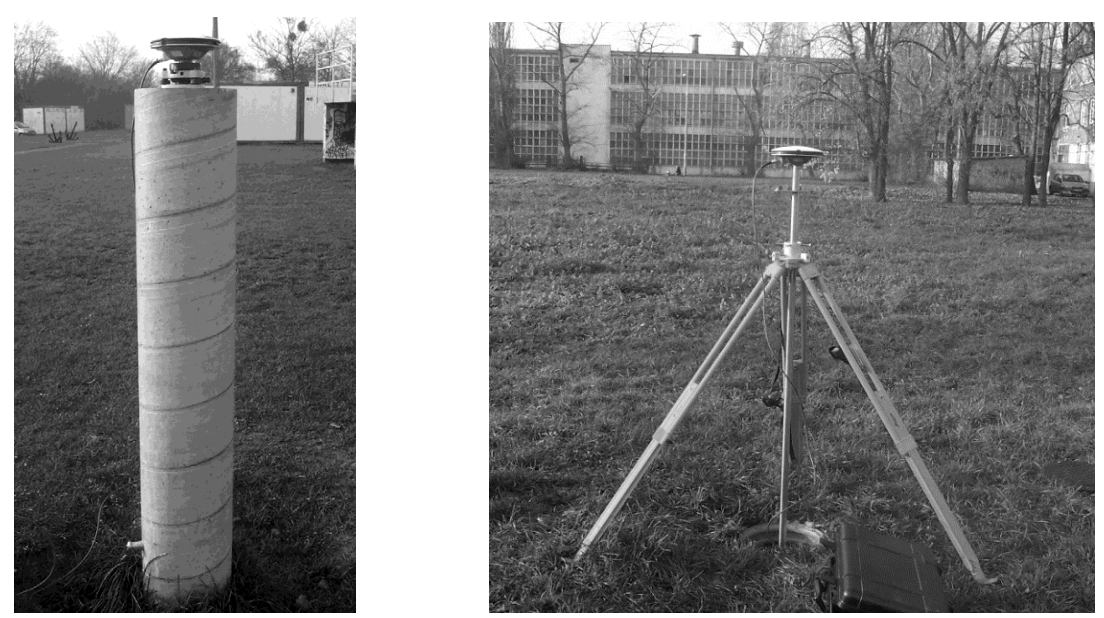

Fig. 2 Concrete pillars at a local reference point (left panel) and a special device for forced precise centering of the GPS antenna over a kontrolled point (right panel).

27 controlled points (K01-K27). The reference points were established outside the influence of the mining area (Fig. 1). The controlled points are distributed at the area influenced by the open pit mine.

During every observing campaign, two 8 hours long sessions were conducted at each controlled point. At the same time, six 8-hour sessions were carried out at each of the local reference points. The GPS observations were collected with use of geodetic dualfrequency receivers namely: Ashtech Z-XII, Ashtech Z-Xtreme, Javad Alpha, Topcon HiperPro and Trimble SPS 882. A forced centering of GNSS antennas were used at all points. At the reference points, the GNSS antennas were mounted on concrete pillars (Fig. 2). At the controlled points, the antennas were mounted using special metal poles for forced centering, which are patented by the University of Warmia and Mazury in Olsztyn (Fig. 2). The applied metal poles are of a fixed length $(\sim 2.2 \mathrm{~m})$ determined with precision of $0.1 \mathrm{~mm}$. This allows for obtaining a high repeatability of the height component determination. On the other hand, horizontal centering of the pole is performed with a bubble level. The precision of the horizontal centering is lower than the height one and is estimated at the level of $2 \mathrm{~mm}$.

\subsection{GPS DATA PROCESSING IN PRECISE LOCAL NETWORK}

In the Figure 3 a flow scheme of the controlled point displacements determination with the GPS local 


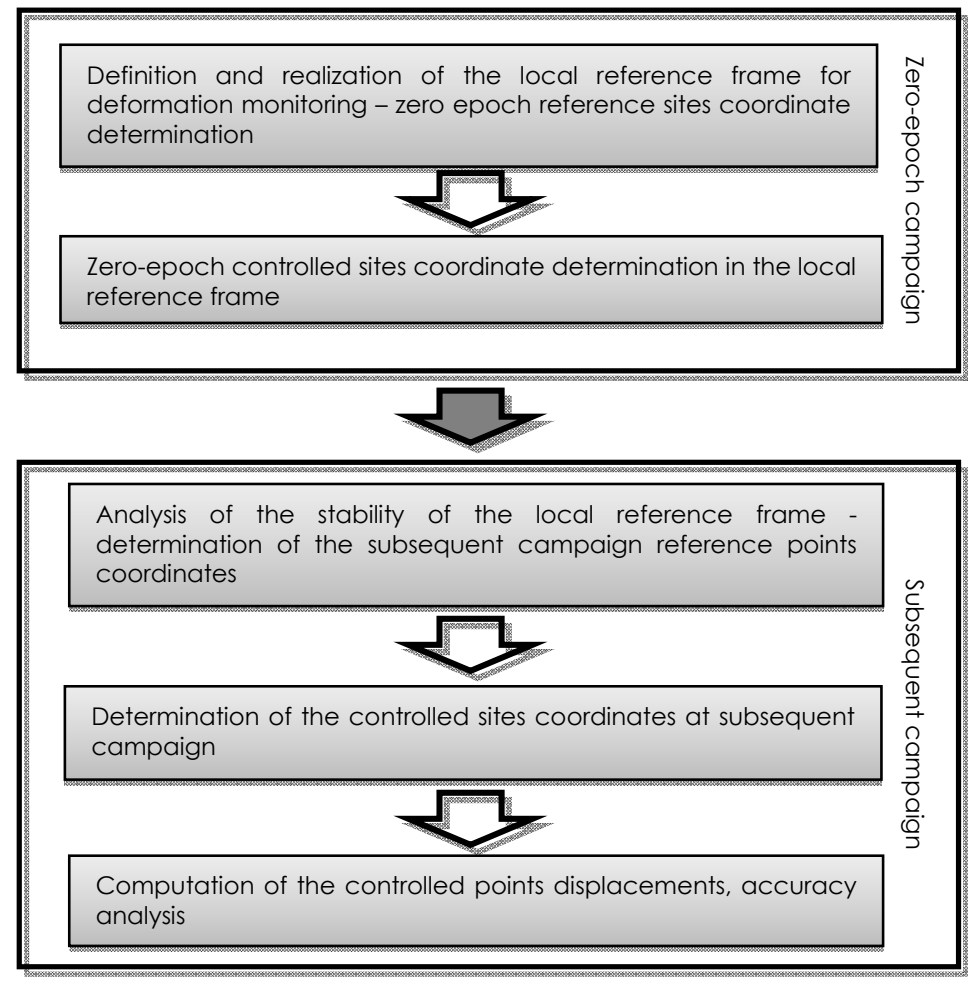

Fig. 3 Scheme of the controlled points displacements determination in local GPS network at investigated area.

network processing is presented. Please note that GPS data processing was divided into two parts. Firstly, it was required to definite and realize the local reference frame for the deformation monitoring. In this step, the initial (zero-epoch) coordinates of the three local reference points (R01-R03) were determined. In the next step, the zero-epoch coordinates of the controlled points (K01-K27) were determined by the processing of the local GPS network (Fig. 1).

On the other hand, the subsequent campaigns observations were processed in three-step procedure (Fig. 3). Before the computation of the actual (campaign) controlled point coordinates, the stability of the local reference points $(R x x)$ was evaluated. The actual controlled point coordinates were determined in the local network processing in relation to the local reference points. In the last step, the controlled point displacements were determined together with their accuracy analysis. Also, statistical significance of the displacements was evaluated. The controlled point displacements were computed as local topocentric coordinates (North, East, Up) differences between current and zero-epoch campaign.

The initial (zero-epoch) coordinates of the reference points $(R x x)$ were determined in relation to three permanent IGS stations: JOZE, LAMA and BOR1 (Fig. 4). The reference points realize the local reference frame for the investigated research area. This frame is based on the ITRF2005 (International Terrestrial Reference Frame) for epoch 2008.12.11 00:00. In order to determine the zero-epoch coordinates, a special GNSS data postprocessing strategy was applied. In this strategy, only independent baselines were processed. Their lengths varied from $102 \mathrm{~km}$ to $247 \mathrm{~km}$ (Fig. 4). Six 8-hour sessions were processed. The data processing interval was set to 30 seconds for the float solution and 60 seconds for the fixed one. A "ionosphere free" linear combination of GPS signals was applied for the outliers detection and the fixed solution. The SIGMA L5\&L3 method was used for the ambiguity resolution using wide lane and narrow lane linear combinations. Absolute antenna phase center variations and final precise satellite orbits from IGS were applied (Dow et al., 2009). The regional ionosphere model from CODE (Center for Orbit Determination in Europe) was used to mitigate the influence of the dispersive part of the atmosphere during the ambiguity resolution (Schaer, 1999). Tropospheric hydrostatic delay was calculated using the Saastamoinen model. Wet part of the tropospheric delay was estimated with 1-hour interval using the Wet Niell mapping function (Niell, 1996). The elevation mask was set to $10^{\circ}$. This strategy allowed for estimation of the zero-epoch coordinates of the reference points with the estimated root mean square error of $2.1 \mathrm{~mm}, 2.1 \mathrm{~mm}$ and $2.3 \mathrm{~mm}$ for $N, E, U$ components, respectively.

Determination of the zero-epoch and actual/periodic coordinates of the control points $(K x x)$ were performed with the application of a different data processing strategy suitable for short baselines $(<15 \mathrm{~km})$. The strategy assumed using of the L1 carrier phase observations, SIGMA L1 ambiguity resolution and $10^{\circ}$ elevation mask. Similarly, the 


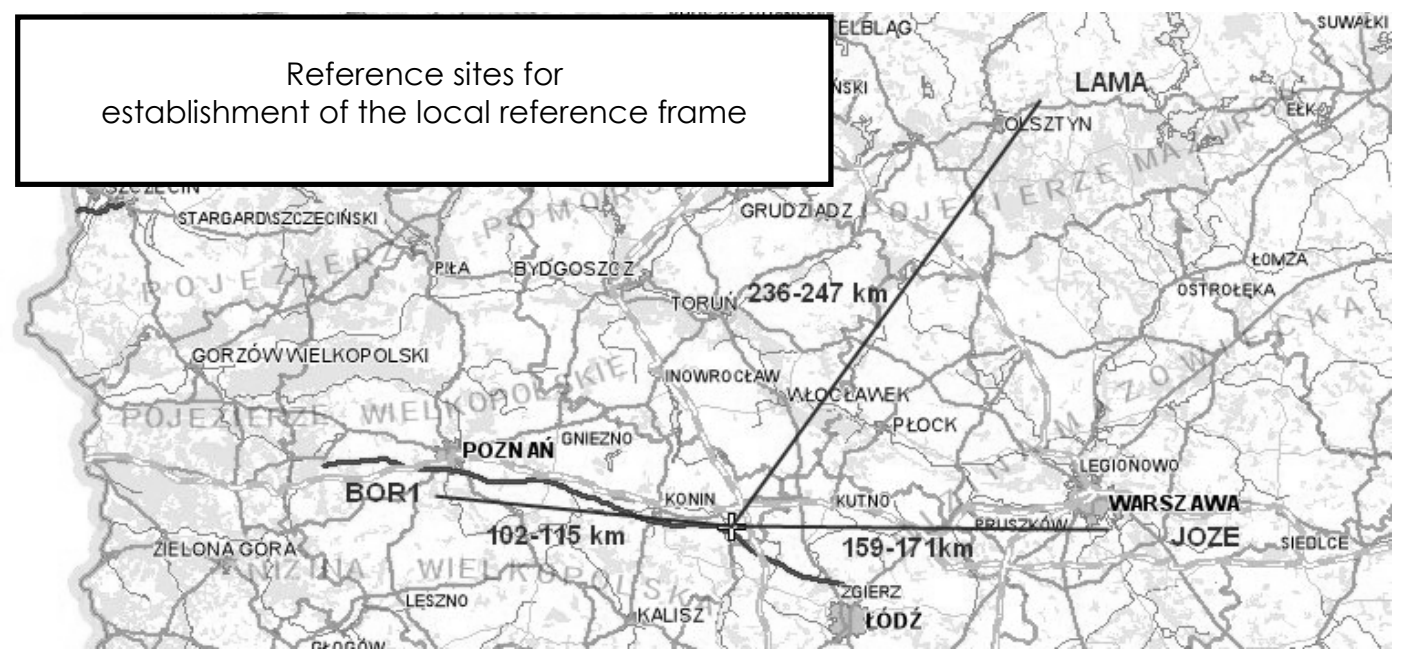

Fig. 4 IGS reference points for establishment of the local reference frame.

Table 1 Linear residuals of the Helmert transformation between the first and subsequent campaigns.

\begin{tabular}{|c|c|c|c|c|c|c|c|c|c|c|c|c|}
\hline \multirow[b]{2}{*}{ campaigns } & \multicolumn{4}{|c|}{$\mathbf{d N}[\mathrm{mm}]$} & \multicolumn{4}{|c|}{$\mathbf{d E}[\mathrm{mm}]$} & \multicolumn{4}{|c|}{$\mathbf{d U}[\mathrm{mm}]$} \\
\hline & 1 and 2 & 1 and 3 & 1 and 4 & 1 and 5 & 1 and 2 & 1 and 3 & 1 and 4 & 1 and 5 & 1 and 2 & 1 and 3 & 1 and 4 & 1 and 5 \\
\hline R01 & 0.5 & -0.5 & -1.3 & -1.9 & 0.2 & 0.1 & 0.4 & -0.4 & 1.5 & -0.4 & 4.0 & -1.2 \\
\hline R02 & 0.7 & 0.6 & 0.6 & -1.0 & 0.7 & 0.8 & 0.6 & 0.8 & 0.3 & 0.6 & -2.0 & 0.6 \\
\hline R03 & -1.2 & -0.1 & 0.7 & 2.9 & -0.9 & -0.8 & -0.9 & -0.4 & -1.8 & -0.2 & -2.0 & 0.6 \\
\hline
\end{tabular}

precise satellite orbits from IGS as well as the absolute antenna phase center variations were applied. The regional ionospheric CODE model and full Niell troposphere model without ZTD estimation were used for the ionospheric and tropospheric delay mitigation, respectively. The detailed procedure applied for the GPS data processing using Bernese 5.0 is given in (Baryła and Paziewski, 2012) and summarized below (task and Bernese module):

- Earth orientation parameters import - POLUPD module;

- precise orbits in sp3 format import and calculation of standard orbits - ORBGEN module;

- RINEX import and conversion to the Bernese format - RXOBV3 module;

- receiver's clock synchronization - CODSPP module;

- independent baselines forming - SINGDIF module;

- triple difference data screening and cycle-slip detection - MAUPRP module;

- model's parameters preliminary estimation GPSEST module;

- $\quad$ outliers detection and elimination - RESRMS and SATMARK modules;
- ambiguity resolution, - GPSEST module (SIGMA method);

- model's parameters final estimation with the integer ambiguity introduction - GPSEST module;

- normal equations combined adjustment/final session solution - ADDNEQ2 module;

- final campaign coordinates adjustment and session-wise repeatability - COMPAR module.

\section{RESULTS}

The analysis of the stability of the local reference frame was carried out when processing each campaign. The 3D Helmert transformation without the scale parameter between zero- and actual coordinates of the local reference points was used in order to detect outstanding residuals. The linear transformation residuals between $1^{\text {st }}$ and the subsequent campaigns are presented in Table 1. These values were the indicators of the local reference frame stability. The majority of the residuals were smaller than $\pm 2.0 \mathrm{~mm}$ for each of the components. The largest residual $( \pm 4.0 \mathrm{~mm})$ was observed for height component between $1^{\text {st }}$ and $4^{\text {th }}$ campaign. However, these values were still below the predefined threshold, thus the local reference frame was considered stable within the limits of the resulting coordinates' precision. 

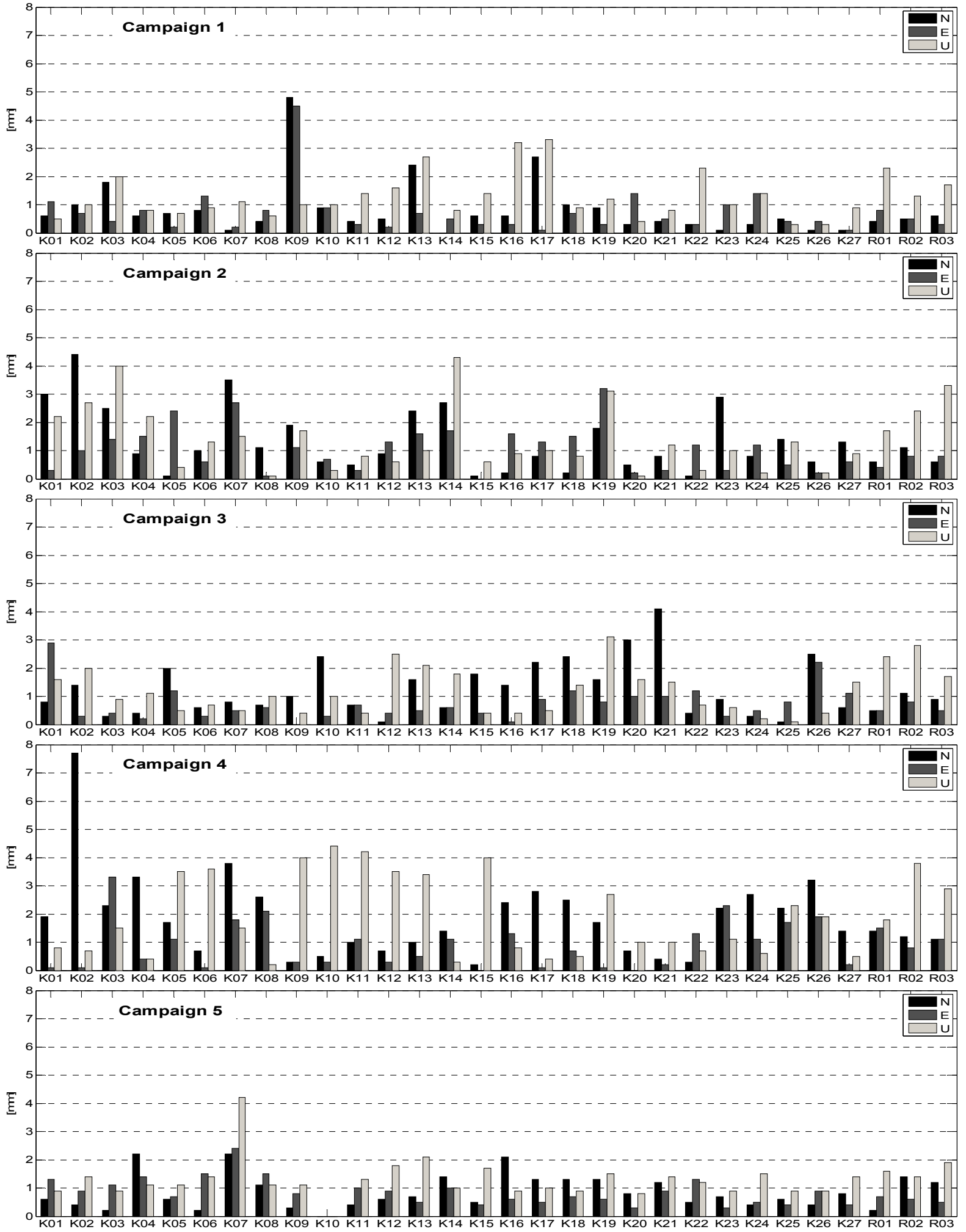

Fig. 5 Repeatability of the reference and the control points' coordinates between the sessions in each campaign.

Figure 5 shows coordinate component standard deviations obtained from the reference and the control points' coordinates in the subsequent sessions within each campaign. Please note that the reference points were surveyed in six, and the control points in two sessions during each campaign. These values may serve as an indicator of the accuracy of the actual camaign coordinates. Moreover these quantities help to detect and eliminate gross errors. Most of the values are smaller than $2 \mathrm{~mm}$ for the horizontal and $3 \mathrm{~mm}$ for the vertical coordinate components. During the $5^{\text {th }}$ campaign, the repeatability of K10 controlled 

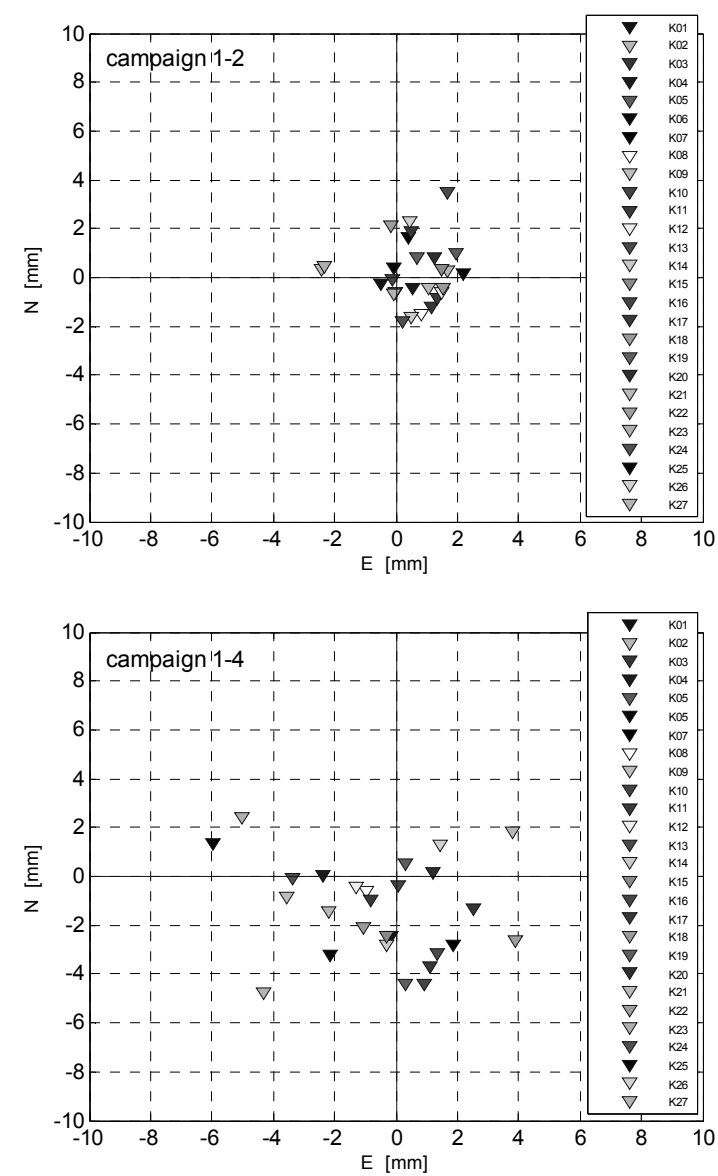
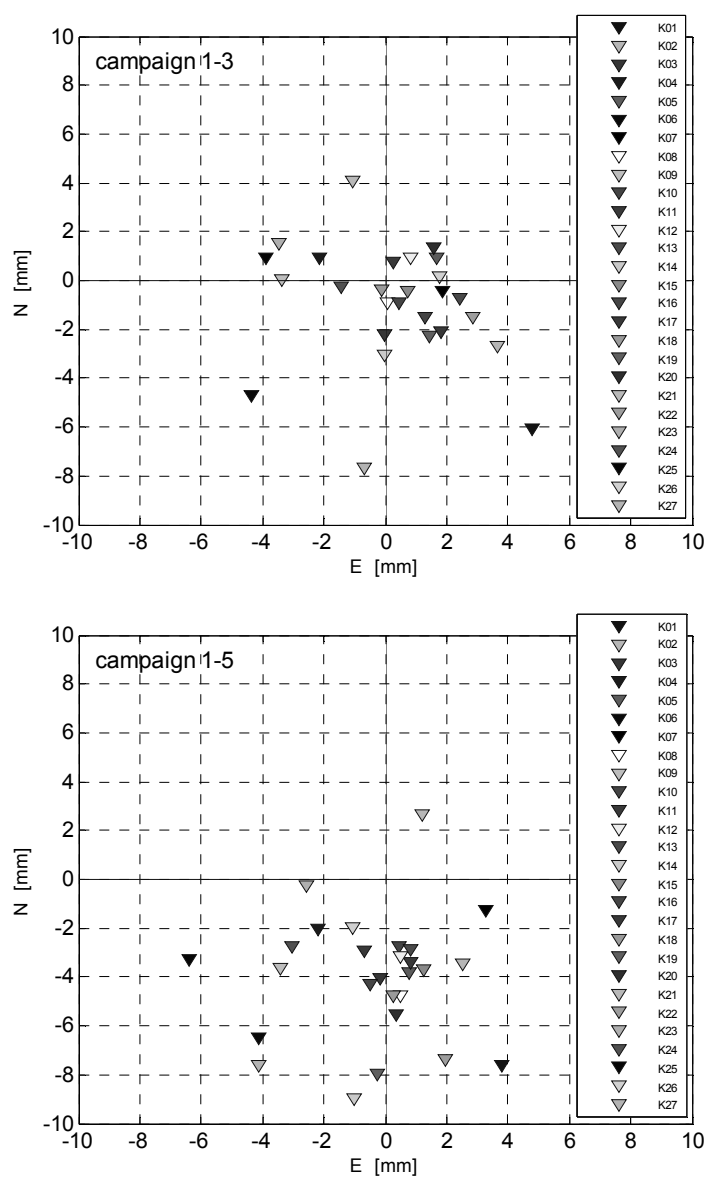

Fig. 6 Horizontal displacements of the controlled points obtained from five campaigns.

point was not calculated due to the equipment failure only one 8-hour session was processed. The incidental few millimeters errors ( $8 \mathrm{~mm}$ at $\mathrm{K} 02$ at $4^{\text {th }}$ campaign) were most probably caused by not equal subsidence of the geodetic tripods during the observing session. It should be noticed that the atmospheric conditions during this one week-long campaign were not stable, with the occurrence of heavy rainfalls. In such conditions, a water absorption by ground was observed, thus tripods at few points were sensitive to subsidence.

Figure 6 depicts differences between the horizontal coordinates of the control points (horizontal displacements) obtained from five measurement campaigns. The $1^{\text {st }}$ campaign coordinates are treated as the reference, and the next campaigns are compared to that reference. Generally, it can be noticed that the differences of the horizontal coordinates between campaign 1 and 2 are the smallest and do not exceed $4 \mathrm{~mm}$. Differences for the subsequent campaigns are larger and amount to maximum of about $9 \mathrm{~mm}$ for the $5^{\text {th }}$ campaign. Horizontal displacements can be characterized rather as random, with slight southward trend. However, these values still cannot be regarded as statistically significant with the accepted $95 \%$ confidence level. Only statistically significant displacements can be deeply analyzed in terms of the trend estimation.

Figure 7 presents the vertical displacements, which are of the highest interest in the area of the open pit mine Koźmin. In general, the most of the controlled points have slightly subsided. Almost in all cases, the displacements of the vertical coordinates are within $\pm 5 \mathrm{~mm}$ range. The geatest displacements were observed at the point $\mathrm{K} 22$ what may result from a bias in its coordinates estimated in the $1^{\text {st }}$ campaign. Again, in case of most of the controlled points, the smallest vertical displacements were obtained beetween the $1^{\text {st }}$ and the $2^{\text {nd }}$ campaign. As it can be seen in Figure 7, the vertical displacements of several controlled points have positive, but very small value. This can be noticed at K09, K10, K11 points. In general, most of the vertical and horizontal displacements are within the limit of the coordinate precision that we estimate at $\pm 3 \mathrm{~mm}$ level and cannot be considered as statistically significant.

\section{CONCLUSIONS}

The presented accuracy assessment of the ground deformation monitoring with the use of the GPS 


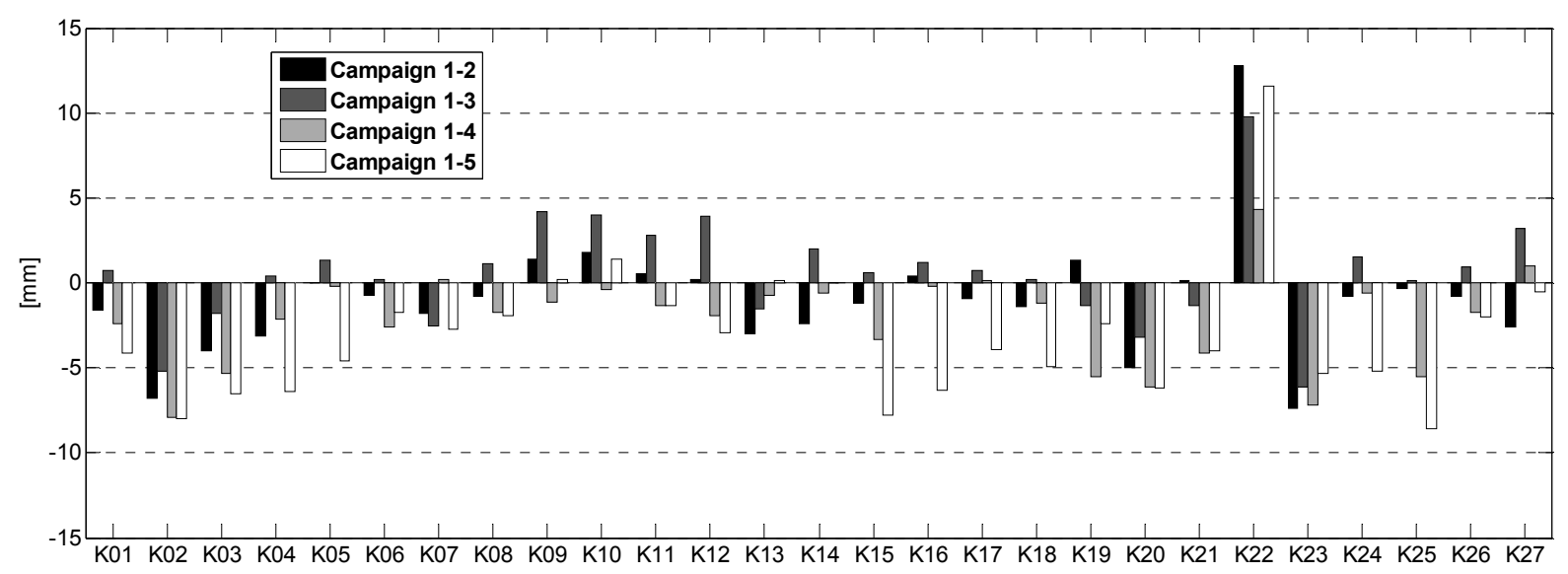

Fig. 7 Vertical displacements of the controlled points obtained from five campaigns.

technology proved that it is possible to achieve a few millimeter accuracy of the displacements for each coordinate component. In specific, the presented methodology allowed to reach $\pm 3 \mathrm{~mm}$ accuracy of the actual controlled points 3D coordinates. However, it should be noticed that there were observed incidental outliers in the obtained coordinate components. The outliers are mostly caused by local surveying conditions, like rainfalls, etc..

The values of the horizontal displacements for each of the campaign never exceeded $\pm 9 \mathrm{~mm}$ and present a slight southward trend. At the same time, most of the horizontal displacements were within $\pm 8 \mathrm{~mm}$ range with predominant downward trend. Additional analysis with the use of the Helmert transformation suggested stability of the local reference frame realized by three local reference points.

The obtained accuracy confirms the usefulness of the GPS technology for precise ground deformation monitoring. The majority of the values of the determined vertical and horizontal displacements are within the range of the $95 \%$ statistical confidence level. This indicate on the insignificance of the resulting displacements. On this basis we can conclude that during a 5-year period the controlled points were stable (within the accepted confidence level).

\section{REFERENCES}

Baryła, R., Wielgosz, P., Paziewski, J. and Błaszczyk, S.: 2011, Principles of ground deformation monitoring at open pit mine with use of GPS technology: KWB "Adamów" in Turek case study. Reports on Geodesy, No. 1 (90), 23-30.

Baryła, R. and Paziewski, J.: 2012, Foundations of ground deformation monitoring on basis of GPS control network, Bulletin Of the Military University of Technology, 2, 39-57, (in Polish).

Chen, Y., Ding, X., Huang, D. and Zhu, J.: 2000, A multiantenna GPS system for local area deformation monitoring. Earth Planets Space, 52, 873-876.
Dach, R., Hugentobler, U., Fridez, P. and Meindl, M.: 2007, Bernese GPS Software version 5.0. Stämpfli Publications AG, Bern.

Dow, J.M., Neilan, R.E. and Rizos, C.: 2009, The International GNSS Service in a changing landscape of Global Navigation Satellite Systems. Journal of Geodesy, 83, 191-198. DOI: $10.1007 / \mathrm{s} 00190-008-0300-3$

Gili, J.A. Corominas, J. and Rius, J.: 2000, Using Global Positioning System techniques in landslide monitoring. Engineering Geology, 55, No. 3, 167192.

Görres, B., Campbell, J., Becker, M. and Siemes, M.: 2006. Absolute calibration of GPS antennas: laboratory results and comparison with field and robot techniques. GPS Solutions, 10(2), 136-145. DOI: $10.1007 / \mathrm{s} 10291-005-0015-3$

Grejner-Brzezinska, D.A., Kashani, I., Wielgosz, P., Smith, D.A., Spencer, P.S.J., Robertson, D.S., and Mader, G.L.: 2007, Efficiency and reliability of ambiguity resolution in network-based real-time kinematic GPS. Journal of Surveying Engineering, 133, No. 2, 56-65. DOI: 10.1061/(ASCE)0733-9453(2007)133:2(56)

Hadaś, T., Kapłon, J., Bosy, J., Sierny, J. and Wilgan, K.: 2013, Near-real-time regional troposphere models for the GNSS precise point positioning technique. Measurement Science and Technology, 24, No. 5. DOI: $10.1088 / 0957-0233 / 24 / 5 / 055003$

Kashani, I., Wielgosz, P. and Grejner-Brzezinska, D.A.: 2007, The impact of the ionospheric correction latency on long-baseline instantaneous kinematic GPS positioning. Survey Review, 39, No. 305, 238-251. DOI: $10.1179 / 175227007 X 197156$

Krypiak-Gregorczyk, A., Wielgosz P. and Krukowska, M.: 2014, A new Ionosphere Monitoring Service over the ASG-EUPOS Network Stations, In Proceedings: The $9^{\text {th }}$ International Conference "ENVIRONMENTAL ENGINEERING", 22-23 May 2014, Vilnius, Lithuania. DOI: 10.3846/enviro.2014.224

Niell, A.E.: 1996, Global mapping functions for the atmosphere delay at radio wavelengths. Journal of Geophysical Research, 101(B2), 3227-3246. DOI: $10.1029 / 95 J B 03048$

Schaer, S.: 1999, Mapping and predicting the Earth's ionosphere using the Global Positioning System. 
Ph.D. dissertation, Astronomical Institute University of Bern, Bern, 205 pp.

Sieradzki, R., Cherniak, I. and Krankowski, A.: 2013, Nearreal time monitoring of the TEC fluctuations over the northern hemisphere using GNSS permanent networks, Advances In Space Research 52(3), 391402. DOI: $10.1016 /$ j.asr.2013.03.036

Stepniak, K., Baryla, R., Wielgosz, P. and Kurpinski, G.: 2013, Optimal data processing strategy in precise GPS leveling networks. Acta Geodyn. Geomater., 10, No. 4(172), 443-452. DOI: 10.13168/AGG.2013.0044

Urquhart, L., Nievinski, F.G. and Santo, M.C.: 2013, Assessment of troposphere mapping functions using three-dimensional ray-tracing. GPS Solutions, 18, 3, 345-354. DOI 10.1007/s10291-013-0334-8.

Vey, S., Dietrich, R., Fritsche, M., Rülke, A., Rothacher, M. and Steigenberger, P.: 2006, Influence of mapping functions parameters on global GPS network analyses: comparison between NMF and IMF. Geophys. Res. Lett., 33, L01814. DOI: 10.1029/2005GL024361

Wang, G.Q.: 2013, Millimeter-accuracy GPS landslide monitoring using Precise Point Positioning with Single Receiver Phase Ambiguity (PPP-SRPA) resolution: a case study in Puerto Rico. Journal of Geodetic Science, 3(1), 22-31. DOI: $10.2478 /$ jogs-2013-0001

Wielgosz, P., Paziewski, J. and Baryla, R.: 2011, On constraining zenith tropospheric delays in processing of local GPS networks with Bernese software. Survey Review, 43, No. 323, 472-483.

DOI: $10.1179 / 003962611 X 13117748891877$ 